\title{
Cytochrome P450 single nucleotide polymorphisms in an indigenous Tanzanian population: a concern about the metabolism of artemisinin-based combinations
}

Karol J Marwa ${ }^{* *}$, Theresa Schmidt ${ }^{2}$, Maria Sjögren², Omary MS Minzi ${ }^{3}$, Erasmus Kamugisha ${ }^{4}$ and Göte Swedberg ${ }^{2}$

\begin{abstract}
Background: Artemisinin-based combinations currently recommended for treatment of uncomplicated Plasmodium falciparum malaria in many countries of sub-Saharan Africa are substrates of CYP enzymes. The cytochrome enzyme system is responsible for metabolism of about $80-90 \%$ of clinically used drugs. It is, therefore, important to obtain the pharmacogenetics of the population in the region with respect to these combinations and thereby enable practitioners to predict treatment outcomes. The aim of this study was to detect and determine allelic frequencies of CYP2C8*2, CYP2C8*3, CYP3A4*1B, CYP3A5*3 and CYP2B6*6 variant alleles in a Tanzanian indigenous population.

Methods: Genomic DNA extraction from blood obtained from 256 participants who escorted patients at Karume Health Centre in Mwanza Tanzania, was carried out using the Gene JET ${ }^{\text {M }}$ Genomic DNA purification kit (Thermo Scientific). Genotyping for the cytochrome P450 variant alleles was performed using predesigned primers. Amplification was done by PCR while differentiation between alleles was done by restriction fragment length polymorphism (PCR-RFLP) (for CYP2C8*2, CYP2C8*3) and sequencing (for CYP2B6*6, CYP3A5*3 and CYP3A4*1B).

Results: CYP2C8*2, CYP2C8*3, CYP3A5*3, CYP3A4*1B and CYP2B6*6 variant allelic frequencies were found to be $19,10,16,78$ and $36 \%$ respectively.

Conclusion: Prevalence of CYP2C8*2, CYP3A5*3, CYP3A4*1B and CYP2B6*6 mutations in a Tanzanian population/ subjects are common. The impact of these point mutations on the metabolism of anti-malarial drugs, particularly artemisinin-based combinations, and their potential drug-drug interactions (DDIs) needs to be further evaluated.
\end{abstract}

Keywords: Cytochrome P450, Artemisinin-based combination therapy, Poor metabolizers, Tanzania, Plasmodium falciparum malaria

\section{Background}

Prevention and treatment of malaria is mainly based on the use of drugs [1]. Treatment response in Plasmodium falciparum malaria depends on various factors such as parasite resistance, host natural immunity, drug quality and the pharmacokinetics of the administered drug [2]. Various studies have been carried out on molecular mechanisms for resistance in malaria chemotherapy [3]. However limited efforts have been made to determine

\footnotetext{
* Correspondence: carol_maro@yahoo.com

'Department of Pharmacology, Catholic University of Health and Allied Sciences, Mwanza, Tanzania

Full list of author information is available at the end of the article
}

genetic polymorphisms in cytochrome P450 enzymes, which may be associated with treatment failure (in extensive metabolizers) as a result of subtherapeutic drug concentrations. Cytochrome P450 (CYP) polymorphisms may also cause toxicity (in slow metabolizers) due to high drug concentrations and emergence or spread of drug resistance (in extensive metabolizers) as a result of subtherapeutic drug concentrations. Recent studies have also associated drug resistant selection with poor metabolizer (PM) phenotype.

The increasing use of artemisinin-based combinations as an effective treatment of resistant malaria demands determination of genetic polymorphisms in the metabolism of 
these drugs and its influence on pharmacokinetic profiles between individuals, adverse drug reactions and clinical outcome.

Polymorphisms in gene encoding for drug- metabolizing enzymes and transporters are associated with individual variation in drug response [4]. The frequency of variant alleles encoding for CYP families varies among populations according to race and ethnic background [5].

Cytochrome P450 metabolize about $80-90 \%$ of clinically used drugs [5-8]. About 40\% of cytochrome P450 dependent-drug metabolism is due to polymorphic enzymes [9]. Polymorphisms occur in all members of the CYP2C subfamily, which are CYP2C8, CYP2C9, CYP2C18 and CYP2C19 [10,11]. The genes for these subfamilies are located on chromosome 10q24 [12]. The role of CYP genes in metabolism varies significantly. For example, CYP2C has been shown to be responsible for metabolism of about $20 \%$ of clinically used drugs and endogenous substances [10].

CYP2C8 has been proven to make up $7 \%$ of the total CYP content of the liver [13] and plays a major role in the metabolism of many clinically available drugs [14-16] accounting for about 5\% of the drugs used clinically [17]. The CYP2C8*2 allele has been reported to be common in Africans, but rare in Asians and Caucasians, whereas $\mathrm{CYP} 2 \mathrm{C} 8 * 3$ has been reported to be common in Caucasians, but rare in Africans or Asians. The latter allele (CYP2C $8 * 3)$ has been associated with a marked reduction in amodiaquine metabolism in Caucasian population [14].

CYP2B6 is located within the CYP2B gene cluster on chromosome 19 [18] and is one of the most polymorphic genes in humans [19]. This gene contributes $2-10 \%$ of the total CYP content [20]. CYP2B6*6 is more frequent in African descent than Caucasoids [21,22] and is associated with raised plasma concentrations of antiretroviral (efavirenz, nevirapine) [19] and anti-malarial drugs (artemisinin and arteether) [1,19].

Cytochrome P450 subfamily CYP3A is the most abundant CYP in the human liver and small intestine [23]. CYP3A4, which is part of CYP3A gene cluster, is involved in the metabolism of approximately $50 \%$ of clinically used drugs $[5,24]$.

CYP3A4 is widely considered to be the dominant CYP3A isoform, but this has been questioned lately when data have shown that the amount of CYP3A5 is much larger than previously assumed in individuals expressing this enzyme [25]. The most common single nucleotide polymorphism (SNP) within the CYP3A4 family is CYP3A4*1B [26], an A to $G$ transition at 392 of the proximal promoter region of the gene. The CYP3A $4 * 1 \mathrm{~B}$ variant allele is shown to be associated with higher expression of CYP3A4 than the wild type allele, which could be caused by a repressor element in the wild type promoter $[27,28]$. CYP3A4*1B is associated with poor metabolism of artemether, lumefantrine [29,30] and quinine [31].

The expression of CYP3A5 in the human liver differs vastly between ethnical groups and within the groups. CYP3A $5 * 3$ is the most frequently recognized nonfunctional allele and one of the most frequent polymorphism among cytochrome $\mathrm{P} 450$ genes being recognized [32]. In Caucasians, the frequency of CYP3A $5 * 3$ has been showed to be $\geq 90 \%$ [33] whilst the occurrence among black Africans differs between 11 and $78 \%$ over the African continent [34].

This study aimed at determining presence of CYP 450 variant alleles (CYP2C $8 * 2, \mathrm{CYP} 2 \mathrm{C} 8 * 3, \mathrm{CYP} 2 \mathrm{~B} 6 * 6$, CYP3A $4 * 1 \mathrm{~B}$ and CYP3A5*3) responsible for the metabolism of artemisinin-based combinations employed in the treatment of uncomplicated malaria and complicated malaria (injectable artesunate) in Tanzania where malaria is endemic.

\section{Methods}

\section{Study area and subjects}

This was a cross-sectional study conducted from April 2013 to April 2014 at Karume Health Centre in Igombe, a semi-urban and malaria meso-endermic area in Ilemela district, Mwanza region, Tanzania, with a population of about 40,000.

\section{Sampling procedure}

Serial sampling method was employed where every third and sixth individual was selected until the sample size was reached.

\section{Blood sample collection and DNA extraction}

Venous blood (1-2 ml) was collected into sterile EDTAcontaining tubes from 256 healthy volunteers after obtaining informed consent from each of the participants. The collected blood was stored at $-40^{\circ} \mathrm{C}$ until genomic DNA extraction was done. Genomic DNA extraction was performed with Gene JET Genomic DNA Purification Kit (Thermo Scientific) according to the manufacturer's instructions.

\section{Genotyping \\ $P C R$ conditions}

The PCR master mix contained $2 \mu \mathrm{l} 1 \mathrm{X}$ Dream Taq Green Buffer (Fermentas), $2 \mu \mathrm{l} 1 \mathrm{mM}$ dNTP Mix (Thermo Scientific), $10 \mu \mathrm{l} 0.5 \mu \mathrm{M}$ reverse primer (Eurofins), $10 \mu \mathrm{l}$ $0.5 \mu \mathrm{M}$ forward primer (Eurofins), $0.25 \mu \mathrm{l} 1.25 \mathrm{U}$ Dream Taq (Thermo Scientific).

PCR amplification was done using primers shown in Table 1 and conditions indicated in Table 2: 2.5\% agarose gel electrophoresis was performed to confirm successful PCR amplification for all samples. 
Table 1 Primers used

\begin{tabular}{|c|c|c|c|}
\hline \multirow[t]{2}{*}{ SNP } & \multicolumn{2}{|l|}{ Primers } & \multirow[t]{2}{*}{ Reference } \\
\hline & Forward & Reverse & \\
\hline CYP3A4*1B & 5'-ATGGCCAAGTCTGGGATGAG-3' & 5'-CTCACCTCTGTTCAGGGAAAC-3' & {$[29,35]$} \\
\hline CYP2B6*6 & 5-'TGAGTGATGGCAGACAATCACA-3' & 5-'CAAGTTGAGCATCTTCAGGAACT-3' & {$[29,35]$} \\
\hline CYP3A5*3 & 5'-TGGAGAGTGGCATAGGAGATAC-3' & $5^{\prime}$ 'CCATACCCCTAGTTGTACGACACA-3' & {$[29,35]$} \\
\hline $\mathrm{CYP} 2 \mathrm{C}^{*} 2$ & 5'-GAACACCAAGCATCACTGGA-3' & GAAATCAAAATACTGATCTGTTGC-3' & {$[36]$} \\
\hline CYP2C8*3 & 5'-CTAAAGGACTTGGTAGGTGCA-3' & 5'-CAGGATGCGCAATGAAGACC-3' & {$[29,35]$} \\
\hline
\end{tabular}

Restriction fragment length polymorphism (PCR-RFLP) for CYP2C $8 * 2$ and $\mathrm{CYP} 2 \mathrm{C} 8 * 3$

The PCR product $(10 \mu \mathrm{L})$ was digested with ten units of Bcll (for CYP2C8*2) in Buffer G (Thermo Scientific) at $55^{\circ} \mathrm{C}$ for three hours or five units of BseRI (for CYP2C8*3) in CutSmart Buffer (New England Biolabs) at $37^{\circ} \mathrm{C}$ for $15 \mathrm{~min}$. Digestion was followed by thermal inactivation of BcII at $80^{\circ} \mathrm{C}$ for $20 \mathrm{~min}$. Five $\mu \mathrm{L}$ of inactivated digested product mixed with a drop of loading dye was analysed by electrophoresis on a $2.5 \%$ agarose gel containing ethidium bromide and visualized under UV light illuminator. The mutant variant of CYP2C8*2 was undigested and observed as a band of $107 \mathrm{bp}$, while wild type DNA was observed as bands of 57 and $50 \mathrm{bp}$ after Bcll digestion. Results with bands at 107, 57 and 50 bp were recorded as heterozygotes. For CYP2C 833 , wild type DNA was observed as bands of 187 and $282 \mathrm{bp}$ after BseRI digestion. Mutants were undigested with one band at $439 \mathrm{bp}$ and heterozygotes yielded bands of 157,282 and $439 \mathrm{bp}$.

\section{CYP3A4*1B, CYP3A5*3 and CYP2B6*6 sequencing}

The PCR products were purified from excess dNTP and primers. To every PCR sample of $15 \mu \mathrm{l}, 7.5 \mu \mathrm{l}$ of ExoSAP Mix was added consisting of $0.019 \mu$ l Exonuclease I $(20 \mathrm{U} / \mu \mathrm{l}), 0.190 \mu \mathrm{l}$ SAP (Shrimp Alkaline Phosphate $1 \mathrm{U} / \mu \mathrm{l}$ ) and $7.290 \mu \mathrm{l}$ of sterile water. The samples were incubated at $37^{\circ} \mathrm{C}$ for $30 \mathrm{~min}$ and then at $90^{\circ} \mathrm{C}$ in a thermocycler for $5 \mathrm{~min}$. In order to prepare for sequencing $2 \mu \mathrm{l}$ of the PCR-product was mixed with $0.4 \mathrm{pmol}$ of the primer and $15.6 \mu \mathrm{l}$ of sterile water. The samples were then sent for sequencing at Uppsala Genome Centre after DNA quantification.

\section{Ethical clearance}

Ethical and study approval was granted by the joint Catholic University of Health and Allied Sciences (CUHAS)/Bugando Medical Centre (BMC) Institutional Review Board. All participants signed a written informed consent.

\section{Statistical analysis}

Allelic frequencies were analysed using SPSS 17, SNPs analysed were evaluated using the online tool HardyWeinberg equilibrium calculator including analysis for ascertainment bias [37].

\section{Results}

A total of 256 subjects were studied for the frequency of SNPs in this study. The median age of the subjects was 28 (IQR 22-35) years and $80.5 \%$ (206/256) were females. All study subjects were natives. Successfully amplified samples were 239 for CYP2C8*2 out of 256,92 for CYP3A4*1B out of 100, 97 for CYP3A5*3 out 100, 100 for CYP2C8*3 out of 100 and 95 for CYP2B6*6 out of 100. For CYP3A4, the A392G mutation known as CYP3A4*1B was investigated. The allele prevalence was found to be $78 \%$ among the 92 subjects included in the study, where $57(62 \%)$ of them were homozygote for the mutant variant. The allele prevalence of the A6986G mutation in CYP3A5, named CYP3A 5*3 was $16 \%$ among 97 subjects. Out of the 97 subjects, only two (2\%) were homozygous for the mutation.

Table 2 PCR conditions employed for various SNPs

\begin{tabular}{|c|c|c|c|c|c|c|}
\hline \multirow[t]{2}{*}{ SNP } & \multicolumn{6}{|l|}{ PCR conditions } \\
\hline & Initial denaturation & Denaturation & Annealing & Extension & Final extension & Hold temp \\
\hline CYP3A4*1B & $94^{\circ} \mathrm{C}$ for $2 \mathrm{~min}$ & $94^{\circ} \mathrm{C}$ for $30 \mathrm{~s}$ (30 cycles) & $60^{\circ} \mathrm{C}$ for $30 \mathrm{~s}$ (30 cycles) & $72^{\circ} \mathrm{C}$ for $90 \mathrm{~s}$ (30 cycles) & $72^{\circ} \mathrm{C}$ for $5 \mathrm{~min}$ & $4^{\circ} \mathrm{C}$ \\
\hline CYP2B6*6 & $96^{\circ} \mathrm{C}$ for $3 \mathrm{~min}$ & $96^{\circ} \mathrm{C}$ for $30 \mathrm{~s}$ (40 cycles) & $64^{\circ} \mathrm{C}$ for $1 \mathrm{~min} 30 \mathrm{~s}$ (40 cycles) & $72^{\circ} \mathrm{C}$ for 1 min $30 \mathrm{~s}$ (40 cycles) & $72^{\circ} \mathrm{C}$ for $10 \mathrm{~min}$ & $4^{\circ} \mathrm{C}$ \\
\hline CYP3A5*3 & $96^{\circ} \mathrm{C}$ for $3 \mathrm{~min}$ & $96^{\circ} \mathrm{C}$ for $30 \mathrm{~s}$ (40 cycles) & $59.3^{\circ} \mathrm{C}$ for $30 \mathrm{~s}$ (40 cycles) & $72^{\circ} \mathrm{C}$ for $30 \mathrm{~s}$ (40 cycles) & $72^{\circ} \mathrm{C}$ for $10 \mathrm{~min}$ & $4^{\circ} \mathrm{C}$ \\
\hline CYP2C8*2 & $96^{\circ} \mathrm{C}$ for $3 \mathrm{~min}$ & $96^{\circ} \mathrm{C}$ for $30 \mathrm{~s}$ (40 cycles) & $56^{\circ} \mathrm{C}$ for $1 \mathrm{~min}$ (40 cycles) & $72^{\circ} \mathrm{C}$ for $1 \mathrm{~min}$ (40 cycles) & $72^{\circ} \mathrm{C}$ for $10 \mathrm{~min}$ & $4^{\circ} \mathrm{C}$ \\
\hline $\mathrm{CYP} 2 \mathrm{C}^{*} 3$ & $96^{\circ} \mathrm{C}$ for $3 \mathrm{~min}$ & $96^{\circ} \mathrm{C}$ for $30 \mathrm{~s}$ (30 cycles) & $64^{\circ} \mathrm{C} 1 \mathrm{~min} 30 \mathrm{~s}$ (30 cycles) & $72^{\circ} \mathrm{C} 1 \mathrm{~min} 30 \mathrm{~s}$ (30 cycles) & $72^{\circ} \mathrm{C}$ for $10 \mathrm{~min}$ & $4^{\circ} \mathrm{C}$ \\
\hline
\end{tabular}


For CYP2C8 the A805T mutation known as CYP2C8*2 was investigated. The allele prevalence was found to be $19 \%$ among the 239 subjects included in the study, where 11 (4.6\%) of them were homozygote for the mutant variant. The G416A mutation (CYP2C8*3) was also analysed, the allele prevalence was identified to be $10 \%$ among the 100 subjects included in the study, where $0(0 \%)$ were homozygote for the mutant variant. For CYP2B6, the G15631T mutation (CYP2B6*6) was investigated. The allele prevalence was found to be $36 \%$ among the 95 subjects included in the study, where 11 (11.6\%) were identified as homozygote for the mutant variant. The allele frequencies were all at Hardy Weinberg equilibrium. These results are in agreement with several earlier studies from other African countries (Tables 3 and 4).

\section{Discussion}

The present study was designed to establish the frequencies of common CYP polymorphisms in Mwanza, Tanzania, as a background for future studies on drug metabolism in clinical trials with anti-malarial drugs. Since artemisinin-based combination therapy (ACT) is the recommended treatment, the study focused on the markers that have been shown to be mostly related with metabolism of anti-malarial drugs, taking into account that some of these mutations have been shown to affect therapeutic response and safety during treatment.

In general, there were no big differences in allele frequencies in comparison with other studies done on African populations (Tables 3 and 4). Despite there being limited information in Tanzania, a few studies on CYP markers done have been performed in Zanzibar, where the population history is different from mainland Tanzania, and Mwanza is geographically distant from Zanzibar. It cannot thus be taken for granted that genetic polymorphisms should be the same in these locations.

Table 3 Allele frequency of CYP3A4*1B and CYP3A5*3 reported from previous studies in African populations

\begin{tabular}{llll}
\hline Country & $\begin{array}{l}\text { Number of } \\
\text { subjects }\end{array}$ & CYP3A4*1B (\%) & CYP3A5*3 (\%) \\
\hline Senegal & 178 & $79[38]$ & - \\
\hline Cameroon & 72 & $78.0[39]$ & - \\
\hline East Africa & & - & $36[40]$ \\
\hline South Africa & 980,987 & $73.0-76.0[41,42]$ & $15.0[41]$ \\
\hline Ghana & $129-204$ & $72.0-81[38,43]$ & $15.0[43]$ \\
\hline Mozambique & 86 & $73.8[44]$ & - \\
\hline Sao Tomé and & 78 & $67.7[44]$ & - \\
\hline Tanzania (Zanzibar) & 99,92 & $69.2[45]$ & $15.8[45]$ \\
\hline Tanzania (Mainland) & 165 & $74[29]$ & $18[29]$ \\
\hline Guinea Bissau & & $74[46]$ & - \\
\hline Zimbabwe & 100 & - & $77.6[47]$ \\
\hline
\end{tabular}

Table 4 Allele frequencies of CYP2C8*2, CYP2C8*3 and CYP2B6*6 reported from previous studies in African populations

\begin{tabular}{llll}
\hline Country number & CYP2C8*2 (\%) & CYP2C8*3 (\%) & CYP2B6*6 (\%) \\
\hline Burundi 60 & - & - & $50.0[48]$ \\
\hline Burkina Faso 275 & $15.5[49]$ & $0.3[49]$ & - \\
\hline Ghana 200 & $17-17.9[50-52]$ & $0[50]$ & $46.9[22]$ \\
\hline Zimbabwe 74 & - & - & $49[53]$ \\
\hline Mozambique 115 & $16.0[54]$ & - & - \\
\hline Senegal 88 & $22.0[36]$ & - & - \\
\hline Tanzania 165 (Zanzibar) & $13.9[55]$ & $2.1[55]$ & - \\
\hline Tanzania 165 (Mainland) & - & - & $34-41.8[29,56]$ \\
\hline South Africa 182 (Xhosa) & - & - & $32.14[57]$ \\
\hline Madagascar 153 & $15.0[36]$ & - & - \\
\hline
\end{tabular}

This study identified similar findings to Zanzibar in the CYP3A5*3 variant allele: 16 vs $15.8 \%$ [45], and for CYP2C8*3 where none of the patients was homozygous mutant [55]. However the study recorded $10 \%$ heterozygous CYP2C8*3 which differs from the $0 \%$ recorded from earlier studies in Zanzibar [55] and a slightly higher CYP2C8*2 (19\%) compared to $13.9 \%$ recorded in Zanzibar [55].

This study identified that $4.6 \%$ of participants were homozygotes for the slow metabolizer allele (CYP2C8*2) representing a significant population at high risk to amodiaquine toxicity due to amodiaquine accumulation, taking into account artesunate-amodiaquine is an alternative to artemether-lumefantrine in the treatment of uncomplicated malaria in Tanzania and other sub-Saharan African countries [1,58].

The mutation A6986G leads to splicing defects in intron 3, introducing a stop codon causing severely decreased enzyme activity [25]. The homozygous mutants of CYP3A $5 \% 3$ was detected in $2 \%$ of the study subjects suggesting poor metabolism to anti-malarial drugs such as quinine, quinidine, artemether, chloroquine, halofantrine, lumefantrine, mefloquine, primaquine, artemisinin, arteether, arterlinic acid and proguanil [1], which suggests that a significant proportion of the population is exposed to toxicity of these anti-malarial drugs, including ACT, such as artemether-lumefantrine and artesunatemefloquine during treatment taking into account that there is a high diversity in CYP3A5 in Africa.

CYP3A5 diversity is higher in East Africa [6,40], which has higher frequencies than other parts of sub-Saharan Africa [6]. The diversity explains a difference between CYP3A $5 * 3$ data from this study and that observed from other areas of East Africa [40], but is similar to data from other parts of Tanzania mainland [29] and South Africa [41]. A high frequency of CYP2B6*6 homozygous mutant allele from this study indicates that a significant 
Table 5 Allele and genotype frequencies of CYP3A4*1B and CYP3A5*3 in Igombe, Tanzania, and expected frequencies according to Hardy Weinberg equilibrium

\begin{tabular}{|c|c|c|c|c|c|c|}
\hline \multirow[t]{2}{*}{ Gene } & \multirow[t]{2}{*}{ SNP } & \multirow[t]{2}{*}{ Allele frequency } & \multicolumn{4}{|c|}{ Genotype frequency } \\
\hline & & & wt/wt & wt/mut & mut/mut & Gene allele \\
\hline \multirow[t]{2}{*}{ CYP3A4 } & A392G & G, 78\% & $5.4 \%(5 / 92)$ & $32.6 \%(30 / 92)$ & $62 \%(57 / 92)$ & CYP3A4*1B wild type \\
\hline & & A, $22 \%$ & & & & \\
\hline \multicolumn{3}{|l|}{ Expected } & 4 & 31 & 56 & \\
\hline \multirow[t]{2}{*}{ CYP3A5 } & A6986G & $\mathrm{G}, 16 \%$ & $70.1(68 / 97)$ & $27.9 \%(27 / 97)$ & $2 \%(2 / 97)$ & CYP3A5*3 wild type \\
\hline & & $\mathrm{A}, 84 \%$ & & & & \\
\hline \multicolumn{3}{|l|}{ Expected } & 68 & 26 & 2 & \\
\hline \multirow[t]{2}{*}{ CYP2C8 } & G416A & $\mathrm{A}, 10 \%$ & $80 \%(80 / 100)$ & $20 \%(20 / 100)$ & $0 \%(0 / 100)$ & CYP2C8*3 wild type \\
\hline & & G, 90\% & & & & \\
\hline \multicolumn{3}{|l|}{ Expected } & 81 & 18 & 1 & \\
\hline \multirow[t]{2}{*}{ CYP2C8 } & A805T & T, $19 \%$ & $66.1(158 / 239)$ & $29.3 \%(70 / 239)$ & $4.6 \%(11 / 239)$ & CYP2C8*2 wild type \\
\hline & & A, $81 \%$ & & & & \\
\hline \multicolumn{3}{|l|}{ Expected } & 159 & 74 & 9 & \\
\hline \multirow[t]{2}{*}{ CYP2B6 } & G15631T & T, 36\% & $39 \%(37 / 95)$ & $49.4 \%(47 / 95)$ & $11.6 \%(11 / 95)$ & CYP2B6*6 wild type \\
\hline & & $\mathrm{G}, 64 \%$ & & & & \\
\hline \multicolumn{2}{|l|}{ Expected } & & 39 & 44 & 12 & \\
\hline
\end{tabular}

Note: wt/wt means homozygous wild type, wt/mut means heterozygous mutant and mut/mut means homozygous mutant.

proportion of the population are poor metabolizers of artemisinin and arteether [1] resulting in an increased risk to toxicity of the above anti-malarial drugs.

For CYP3A4*1B, a very high proportion of the poor metabolizer allele (PM) in the population indicates high risk to artemisinin, artemether and lumefantrine toxicity due to a less efficient metabolism as discussed with CYP3A5*3 and CYP2C8*2 above. The high frequency recorded in this study demonstrates the previous documentations on a higher occurrence of this variant allele in Africans than Caucasians [59]. The high allele frequency observed from the study population is similar to other African populations, Ghana being one example [43]. Population variability for CYP3A4 is also exceptionally high, more than 100-fold [60]. The frequency of the CYP3A4*1B mutation differs between populations. Among Caucasians and Hispanics the frequency is $3-5 \%$, among Asians it seems to be absent [60] while the variant is more common among Africans as shown by findings from this study and previous studies (Tables 3, 4 and 5).

CYP2C8*3 has been shown to affect metabolism to a higher extent than CYP2C8*2. This study did not identify any homozygous patients who are PM of amodiaquine. This finding is not surprising since this variant allele has been shown to be rare/uncommon among indigenous Africans and predominantly concentrated in Caucasians [14]. CYP2C8*3 frequencies recorded in this study are similar to Uganda [61] and other African countries [50].

Findings from this study demonstrate the existence of diverse genetics of the above CYP $450 \mathrm{~s}$ in Tanzania, thus calling for an evaluation of the impact of CYP 450 polymorphisms on metabolism of artemisinin-based combinations and its impact on clinical outcome and toxicity among P. falciparum malaria-infected patients in African populations.

\section{Conclusion}

Prevalence of CYP2C8*2, CYP3A5*3, CYP3A4*1B and CYP2B6*6 mutations are common while CYP2C8*3 mutations are rare in a Tanzanian population. The frequencies recorded in this study are comparable to data obtained from previous studies on African populations. Pharmacogenomics data, such as that presented in this paper, provides a basis for further studies on impact of polymorphism in ACT safety and efficacy.

\section{Competing interests}

The authors declare that they have no competing interests.

\section{Authors' contributions}

KJM participated in proposal development, sample collection, carrying out molecular genetic analysis, data analysis and manuscript drafting. TS and MS carried out molecular genetic analysis and data analysis. OMS, EK and GS participated in proposal development, supervision of the research group and revising and approving the manuscript for publication. All authors read and approved the final manuscript.

\section{Acknowledgements}

We sincerely thank the participants who donated blood and appreciate the contribution of the nurses, laboratory technicians and clinicians at Karume Health Centre, Igombe Mwanza, Tanzania. This work was funded by the Swedish Research Council, Department of Medical Biochemistry and Microbiology, Uppsala University and the Catholic University of Health and Allied Sciences. 


\section{Author details}

'Department of Pharmacology, Catholic University of Health and Allied Sciences, Mwanza, Tanzania. ${ }^{2}$ Institute of Medical Biochemistry and Microbiology, Uppsala University, Uppsala, Sweden. ${ }^{3}$ Unit of Pharmacology and Therapeutics, Muhimbili University of Health and Allied Health Sciences, Dar Es Salaam, Tanzania. ${ }^{4}$ Department of Biochemistry, Catholic University of Health and Allied Sciences, Mwanza, Tanzania.

Received: 23 August 2014 Accepted: 25 October 2014

Published: 3 November 2014

\section{References}

1. Kerb R, Fux R, Morike K, Kremsner PG, Gil JP, Gleiter CH, Schwab M: Pharmacogenetics of antimalarial drugs: effect on metabolism and transport. Lancet Infect Dis 2009, 9:760-774.

2. Obua C, Hellgren U, Ntale M, Gustafsson LL, Ogwal-Okeng JW, Gordi T, Jerling M: Population pharmacokinetics of chloroquine and sulfadoxine and treatment response in children with malaria: suggestions for an improved dose regimen. Br J Clin Pharmacol 2008, 65:493-501.

3. Arav-Boger $\mathrm{R}$, Shapiro TA: Molecular mechanisms of resistance in antimalarial chemotherapy: the unmet challenge. Annu Rev Pharmacol Toxicol 2005, 45:565-585.

4. Shah RR: Pharmacogenetics in drug regulation: promise, potential and pitfalls. Philos Trans R Soc Lond B Biol Sci 2005, 360:1617-1638.

5. Seripa D, Pilotto A, Panza F, Matera MG: Pharmacogenetics of cytochrome P450 (CYP) in the elderly. Ageing Res Rev 2010, 9:457-474.

6. Bains RK: African variation at cytochrome P450 genes evolutionary aspects and the implications for the treatment of infectious diseases. Evol Med Public Health 2013, 2013:118-134.

7. Guengerich FP: Cytochrome P450s and other enzymes in drug metabolism and toxicity. Aaps J 2006, 8:E101-E111.

8. Lynch T, Price A: The effect of cytochrome P450 metabolism on drug response, interactions, and adverse effects. Am Fam Physician 2007, 76:391-396

9. Ingelman-Sundberg M, Oscarson M, McLellan RA: Polymorphic human cytochrome P450 enzymes: an opportunity for individualized drug treatment. Trends Pharmacol Sci 1999, 20:342-349.

10. Goldstein JA: Clinical relevance of genetic polymorphisms in the human CYP2C subfamily. Br J Clin Pharmacol 2001, 52:349-355.

11. Miners JO, Birkett DJ: Cytochrome P4502C9: an enzyme of major importance in human drug metabolism. Br J Clin Pharmacol 1998, 45:525-538.

12. Finta C, Zaphiropoulos PG: The human CYP2C locus: a prototype for intergenic and exon repetition splicing events. Genomics 2000, 63:433-438.

13. Totah RA, Rettie AE: Cytochrome P450 2C8: substrates, inhibitors, pharmacogenetics, and clinical relevance. Clin Pharmacol Ther 2005, 77:341-352.

14. Daily EB, Aquilante CL: Cytochrome P450 2C8 pharmacogenetics: a review of clinical studies. Pharmacogenomics 2009, 10:1489-1510.

15. Schoch GA, Yano JK, Wester MR, Griffin KJ, Stout CD, Johnson EF: Structure of human microsomal cytochrome P450 2C8: evidence for a peripheral fatty acid binding site. J Biol Chem 2004, 279:9497-9503.

16. Schoch GA, Yano JK, Sansen S, Dansette PM, Stout CD, Johnson EF: Determinants of cytochrome P450 2C8 substrate binding: structures of complexes with montelukast, troglitazone, felodipine, and 9-cis-retinoic acid. J Biol Chem 2008, 283:17227-17237.

17. Naraharisetti SB, Lin YS, Rieder MJ, Marciante KD, Psaty BM, Thummel KE, Totah RA: Human liver expression of CYP2C8: gender, age, and genotype effects. Drug Metab Dispos 2010, 38:889-893.

18. Hoffman SM, Nelson DR, Keeney DS: Organization, structure and evolution of the CYP2 gene cluster on human chromosome 19. Pharmacogenetics 2001, 11:687-698.

19. Zanger UM, Klein K, Saussele T, Blievernicht J, Hofmann MH, Schwab M: Polymorphic CYP2B6: molecular mechanisms and emerging clinical significance. Pharmacogenomics 2007, 8:743-759.

20. Wang H, Tompkins LM: CYP2B6: new insights into a historically overlooked cytochrome P450 isozyme. Curr Drug Metab 2008, 9:598.

21. King J, Aberg JA: Clinical impact of patient population differences and genomic variation in efavirenz therapy. Aids 2008, 22:1709-1717.
22. Klein K, Lang T, Saussele T, Barbosa-Sicard E, Schunck WH, Eichelbaum M, Schwab M, Zanger UM: Genetic variability of CYP2B6 in populations of African and Asian origin: allele frequencies, novel functional variants, and possible implications for anti-HIV therapy with efavirenz. Pharmacogenet Genomics 2005, 15:861-873.

23. Shimada T, Yamazaki H, Mimura M, Inui Y, Guengerich FP: Interindividual variations in human liver cytochrome $\mathrm{P}-450$ enzymes involved in the oxidation of drugs, carcinogens and toxic chemicals: studies with liver microsomes of 30 Japanese and 30 Caucasians. J Pharmacol Exp Ther 1994, 270:414-423.

24. Thummel KE, Wilkinson GR: In vitro and in vivo drug interactions involving human CYP3A. Annu Rev Pharmacol Toxicol 1998, 38:389-430.

25. Kuehl P, Zhang J, Lin Y, Lamba J, Assem M, Schuetz J, Watkins PB, Daly A, Wrighton SA, Hall SD, Maurel P, Relling M, Brimer C, Yasuda K, Venkataramanan R, Strom S, Thummel K, Boguski MS, Schuetz E: Sequence diversity in CYP3A promoters and characterization of the genetic basis of polymorphic CYP3A5 expression. Nat Genet 2001, 27:383-391.

26. Lamba JK, Lin YS, Schuetz EG, Thummel KE: Genetic contribution to variable human CYP3A-mediated metabolism. Adv Drug Deliv Rev 2002, 54:1271-1294

27. Amirimani B, Ning B, Deitz AC, Weber BL, Kadlubar FF, Rebbeck TR: Increased transcriptional activity of the CYP3A4*1B promoter variant. Environ Mol Mutagen 2003, 42:299-305.

28. Hashimoto H, Toide K, Kitamura R, Fujita M, Tagawa S, Itoh S, Kamataki T: Gene structure of CYP3A4, an adult-specific form of cytochrome P450 in human livers, and its transcriptional control. Eur J Biochem 1993, 218:585-595.

29. Staehli Hodel EM, Csajka C, Ariey F, Guidi M, Kabanywanyi AM, Duong S, Decosterd LA, Olliaro P, Beck HP, Genton B: Effect of single nucleotide polymorphisms in cytochrome $\mathrm{P} 450$ isoenzyme and $\mathrm{N}$-acetyltransferase 2 genes on the metabolism of artemisinin-based combination therapies in malaria patients from Cambodia and Tanzania. Antimicrob Agents Chemother 2013, 57:950-958.

30. Piedade R, Gil JP: The pharmacogenetics of antimalaria artemisinin combination therapy. Expert Opin Drug Metab Toxicol 2011, 7:1185-1200.

31. Rodriguez-Antona C, Sayi JG, Gustafsson LL, Bertilsson L, IngelmanSundberg M: Phenotype-genotype variability in the human CYP3A locus as assessed by the probe drug quinine and analyses of variant CYP3A4 alleles. Biochem Biophys Res Commun 2005, 338:299-305.

32. Temesvari M, Kobori L, Paulik J, Sarvary E, Belic A, Monostory K: Estimation of drug-metabolizing capacity by cytochrome P450 genotyping and expression. J Pharmacol Exp Ther 2012, 341:294-305.

33. Zhou SF, Liu JP, Chowbay B: Polymorphism of human cytochrome P450 enzymes and its clinical impact. Drug Metab Rev 2009, 41:89-295.

34. Alessandrini M, Asfaha S, Dodgen TM, Warnich L, Pepper MS: Cytochrome P450 pharmacogenetics in African populations. Drug Metab Rev 2013, 45:253-275.

35. Hodel EM, Ley SD, Qi W, Ariey F, Genton B, Beck HP: A microarray-based system for the simultaneous analysis of single nucleotide polymorphisms in human genes involved in the metabolism of anti-malarial drugs. Malar $\mathrm{J}$ 2009, 8:285.

36. Paganotti GM, Gramolelli S, Tabacchi F, Russo G, Modiano D, Coluzzi M, Romano R: Distribution of human CYP2C8*2 allele in three different African populations. Malar J 2012, 11:125

37. Rodriguez S, Gaunt TR, Day IN: Hardy-Weinberg equilibrium testing of biological ascertainment for Mendelian randomization studies. Am J Epidemiol 2009, 169:505-514

38. Zeigler-Johnson C, Walker A, Mancke B, Spangler E, Jalloh M, McBride S, Deitz A, Malkowicz S, Ofori-Adjei D, Gueye S: Ethnic differences in the frequency of prostate cancer susceptibility alleles at SRD5A2 and CYP3A4. Hum Hered 2002, 54:13-21.

39. Swart M, Skelton M, Wonkam A, Kannemeyer L, Dandara C: CYP1A2, CYP2A6, CYP2B6, CYP3A4 and CYP3A5 polymorphisms in two Bantuspeaking populations from Cameroon and South Africa: implications for global pharmacogenetics. Curr Pharmacogenomics Personalized Med 2012, 10:43-53.

40. Bains RK, Kovacevic M, Plaster CA, Tarekegn A, Bekele E, Bradman NN, Thomas MG: Molecular diversity and population structure at the cytochrome P450 3A5 gene in Africa. BMC Genet 2013, 14:1-18.

41. Dandara C, Lombard Z, Du Plooy I, McLellan T, Norris SA, Ramsay M: Genetic variants in CYP $(-1 A 2,-2 C 9,-2 C 19,-3 A 4$ and $-3 A 5)$, VKORC1 and 
$A B C B 1$ genes in a black South African population: a window into diversity. Pharmacogenomics 2011, 12:1663-1670.

42. Drogemoller B, Plummer M, Korkie L, Agenbag G, Dunaiski A, Niehaus D, Koen L, Gebhardt S, Schneider N, Olckers A, Wright G, Warnich L: Characterization of the genetic variation present in CYP3A4 in three South African populations. Front Genet 2013, 4:17.

43. Kudzi W, Dodoo AN, Mills JJ: Genetic polymorphisms in MDR1, CYP3A4 and CYP3A5 genes in a Ghanaian population: a plausible explanation for altered metabolism of ivermectin in humans? BMC Med Genet 2010, 11:111.

44. Oliveira E, Pereira R, Amorim A, McLeod H, Prata MJ: Patterns of pharmacogenetic diversity in African populations: role of ancient and recent history. Pharmacogenomics 2009, 10:1413-1422.

45. Ferreira PE, Veiga MI, Cavaco I, Martins JP, Andersson B, Mushin S, Ali AS, Bhattarai A, Ribeiro V, Bjorkman A, Gil JP: Polymorphism of antimalaria drug metabolizing, nuclear receptor, and drug transport genes among malaria patients in Zanzibar, East Africa. Ther Drug Monit 2008, 30:10-15.

46. Cavaco I, Reis R, Gil JP, Ribeiro V: CYP3A4*1B and NAT2*14 alleles in a native African population. Clin Chem Lab Med 2003, 41:606-609.

47. Roy J-N, Lajoie J, Zijenah LS, Barama A, Poirier C, Ward BJ, Roger M: CYP3A5 genetic polymorphisms in different ethnic populations. Drug Metab Dispos 2005, 33:884-887.

48. Calcagno A, D'Avolio A, Simiele M, Cusato J, Rostagno R, Libanore V, Baietto L, Siccardi M, Bonora S, Di Perri G: Influence of CYP2B6 and ABCB1 SNPs on nevirapine plasma concentrations in Burundese HIV-positive patients using dried sample spot devices. Br J Clin Pharmacol 2012, 74:134-140.

49. Parikh S, Ouedraogo JB, Goldstein JA, Rosenthal PJ, Kroetz DL: Amodiaquine metabolism is impaired by common polymorphisms in CYP2C8: implications for malaria treatment in Africa. Clin Pharmacol Ther 2007, 82:197-203.

50. Kudzi W, Dodoo AN, Mills Jj: Characterisation of CYP2C8, CYP2C9 and CYP2C19 polymorphisms in a Ghanaian population. BMC Med Genet 2009, 10:124.

51. Adjei GO, Kristensen K, Goka BQ, Hoegberg LC, Alifrangis M, Rodrigues OP, Kurtzhals JA: Effect of concomitant artesunate administration and cytochrome $\mathrm{P} 4502 \mathrm{C} 8$ polymorphisms on the pharmacokinetics of amodiaquine in Ghanaian children with uncomplicated malaria. Antimicrob Agents Chemother 2008, 52:4400-4406.

52. Rower S, Bienzle U, Weise A, Lambertz U, Forst T, Otchwemah RN, Pfutzner A, Mockenhaupt FP: High prevalence of the cytochrome P450 2C8*2 mutation in Northern Ghana. Trop Med Int Health 2005, 10:1271-1273.

53. Nyakutira C, Roshammar D, Chigutsa E, Chonzi P, Ashton M, Nhachi C, Masimirembwa C: High prevalence of the CYP2B6 516G $\rightarrow T\left({ }^{*} 6\right)$ variant and effect on the population pharmacokinetics of efavirenz in HIV/AIDS outpatients in Zimbabwe. Eur J Clin Pharmacol 2008, 64:357-365.

54. Arnaldo P, Thompson RE, Lopes MQ, Suffys PN, Santos AR: Frequencies of cytochrome P450 2B6 and 2C8 allelic variants in the Mozambican population. Malays J Med Sci 2013, 20:13-23.

55. Cavaco I, Stromberg-Norklit J, Kaneko A, Msellem MI, Dahoma M, Ribeiro VL, Bjorkman A, Gil JP: CYP2C8 polymorphism frequencies among malaria patients in Zanzibar. Eur J Clin Pharmacol 2005, 61:15-18.

56. Ngaimisi E, Habtewold A, Minzi O, Makonnen E, Mugusi S, Amogne W, Yimer G, Riedel KD, Janabi M, Aderaye G, Mugusi F, Bertilsson L, Aklillu E, Burhenne J: Importance of ethnicity, CYP2B6 and ABCB1 genotype for efavirenz pharmacokinetics and treatment outcomes: a parallel-group prospective cohort study in two sub-Saharan Africa populations. PLoS One 2013, 8:e67946.

57. Parathyras J, Gebhardt S, Hillermann-Rebello R, Grobbelaar N, Venter M, Warnich $L$ : A pharmacogenetic study of CD4 recovery in response to HIV antiretroviral therapy in two South African population groups. J Hum Genet 2009, 54:261-265.

58. Maiteki-Sebuguzi C, Jagannathan P, Yau VM, Clark TD, Njama-Meya D, Nzarubara B, Talisuna AO, Kamya MR, Rosenthal PJ, Dorsey G, Staedke SG: Safety and tolerability of combination antimalarial therapies for uncomplicated falciparum malaria in Ugandan children. Malar J 2008, 7:106.

59. Tayeb MT, Clark C, Ameyaw MM, Haites NE, Evans DA, Tariq M, Mobarek A, Ofori-Adjei D, McLeod HL: CYP3A4 promoter variant in Saudi, Ghanaian and Scottish Caucasian populations. Pharmacogenetics 2000, 10:753-756.
60. Zanger UM, Schwab M: Cytochrome P450 enzymes in drug metabolism: regulation of gene expression, enzyme activities, and impact of genetic variation. Pharmacol Ther 2013, 138:103-141.

61. Paganotti GM, Cosentino V, Russo G, Tabacchi F, Gramolelli S, Coluzzi M, Romano R: Absence of the human CYP2C8*3 allele in Ugandan children exposed to Plasmodium falciparum malaria. Infect Genet Evol 2014, 27:432-435

doi:10.1186/1475-2875-13-420

Cite this article as: Marwa et al:: Cytochrome P450 single nucleotide polymorphisms in an indigenous Tanzanian population: a concern about the metabolism of artemisinin-based combinations. Malaria Journal 2014 13:420.

\section{Submit your next manuscript to BioMed Central and take full advantage of:}

- Convenient online submission

- Thorough peer review

- No space constraints or color figure charges

- Immediate publication on acceptance

- Inclusion in PubMed, CAS, Scopus and Google Scholar

- Research which is freely available for redistribution 